\title{
Los orígenes del Instituto de Investigaciones Históricas de la Facultad de Filosofía y Letras de la Universidad de Buenos Aires
}

Pablo Buchbinder

Instituto de Historia Argentina y Americana "Dr. Emilio Ravignani"-UBA/Conicet, Argentina. Correo electrónico: pbuchbin@retina.ar

Artículo recibido: 24 de noviembre de 2020

Aprobación final: 09 de enero de 2021

\section{Resumen}

El objetivo del artículo consiste en analizar los orígenes del Instituto de Investigaciones Históricas, dependiente de la Facultad de Filosofía y Letras de la Universidad de Buenos Aires. Se analizan sus primeros proyectos y colecciones editoriales en el marco de la profesionalización de los historiadores. Se estudian también los cambios experimentados por el Instituto desde su fundación hasta la década de 1930.

Palabras clave: Universidad, Historiografía, Profesionalización, Archivos.

The Origins of the Institute of Historical Investigations of the School of Philosophy and Literature

\begin{abstract}
The aim of the article is to analyze the origins of the Institute for Historical Research, which depended on the University of Buenos Aires's School of Philosophy and Literature. I investigate its first projects and editorial collections in the framework of the professionalization of historians. The changes experienced by the Institute from its foundation until the 1930s are also studied.
\end{abstract}




\section{Los orígenes de la Sección de Investigaciones Históricas}

Una resolución del Consejo Superior de la Universidad de Buenos Aires (UBA, en adelante) de finales de 1921 posibilitó la transformación de la Sección de Investigaciones Históricas de la Facultad de Filosofía y Letras de dicha universidad en el Instituto de Investigaciones Históricas. De este modo se dio un paso más en el proceso de institucionalización de los estudios en esta disciplina en el ámbito universitario. La Sección había sido creada en el año 1905. En 1956, el Instituto adoptaría la denominación de Instituto de Historia Argentina "Emilio Ravignani”, en homenaje a su primer director. A pesar del lugar central que este organismo desempeñó en el proceso de profesionalización e institucionalización de los estudios históricos en la Argentina, sus orígenes y trayectoria han concitado un limitado interés entre los especialistas. A excepción del trabajo que elaboraran hace ya más de un cuarto de siglo Nora Pagano y Miguel Galante (1993: 45-77) y del publicado por María del Carmen Pompert de Valenzuela (1995: 251-270) en un volumen editado por la Academia Nacional de la Historia, además de algunos otro textos de carácter más bien conmemorativo, la trayectoria del Instituto y sobre todo sus primeros pasos no han sido objeto de un análisis en profundidad. Un estudio de esta naturaleza permitiría además contar con un panorama más adecuado de los itinerarios que siguió la construcción de la profesión de historiador en la Argentina de las primeras décadas del siglo XX. Este texto aspira sólo a proponer algunas ideas y líneas de trabajo en ese sentido.

La decisión de crear el Instituto, sobre la base de la Sección, formó parte de un proceso mayor de institucionalización de la actividad científica en el seno de la UBA, que gozó de un particular dinamismo durante los años inmediatamente posteriores a la Reforma Universitaria de 1918. En 1919 Bernardo Houssay había reorganizado el Instituto de Fisiología de la Facultad de Ciencias Médicas. Allí realizaría la mayor parte de las investigaciones, que le permitirían ser galardonado con el Premio Nobel de Medicina en el año 1947. Pero sería la Facultad de Filosofía y Letras la que experimentaría con mayor intensidad el proceso de institucionalización científica de varias de las disciplinas o subdisciplinas que se practicaban en su seno. Entre 1921 y 1942 fueron creados 16 institutos en la Facultad (Buchbinder, 1997). En 1922 se fundaron los de Literatura Argentina y Filología. El primero sería dirigido por Ricardo Rojas. El segundo, organizado bajo la tutela de Ramón Menéndez Pidal, tendría por directores a varios prestigiosos filólogos españoles, entre ellos Amado Alonso. La producción de este último Instituto ocuparía un lugar central a nivel internacional en el desarrollo de la disciplina hasta finales de los años cuarenta. A estos se sumarían más tarde otros centros que dinamizarían la investigación en el ámbito de la UBA y, en particular, en el de la Facultad.

Por otro lado, el itinerario de los proyectos o intentos de creación de organismos especializados en la investigación y la práctica de la Historia en el Río de la Plata registraba ya por entonces varios hitos significativos. Desde mediados del siglo XIX, habían tenido lugar diversos ensayos orientados a la conformación de un espacio consagrado a la sociabilidad de los investigadores del pasado rioplatense 
y, en particular, a la recopilación y publicación de documentos relativos a la historia americana. A través de estas iniciativas, se procuró crear ámbitos para la producción intelectual que permaneciesen al margen de las controversias y luchas políticas. Sin embargo, la inestabilidad y la ausencia de continuidad en términos políticos y administrativos provocaron que estos proyectos no llegaran a consolidarse. El 25 de mayo de 1843 tuvo lugar la formación, en Montevideo, de un Instituto Histórico y Geográfico, entre cuyos fundadores se encontraba Bartolomé Mitre. En 1854, ya en Buenos Aires, este último impulsó la creación de un Instituto Histórico y Geográfico del Río de la Plata. Se aprobó un Reglamento y en las Bases Orgánicas se dispuso que, una vez establecido, el organismo se dirigiría al Gobierno poniéndose bajo su protección. Además se solicitó que, mientras se constituyese en forma definitiva, se le permitiese reunirse en locales públicos (Buchbinder, 1996:58-82). Pero el Instituto se disolvió entre 1859 y 1860 como consecuencia de los acontecimientos que vivió la provincia durante aquellos años. Simultáneamente tuvo lugar, desde la Confederación Argentina, y por iniciativa de Vicente Quesada, un esfuerzo por recopilar y difundir documentación histórica, en particular de las provincias a través de la Revista del Paraná. Ensayos en ese mismo sentido protagonizó Quesada a través de la Revista de Buenos Aires y de la dirección de la Biblioteca Pública de la misma Provincia en las décadas de 1860 y 1870, respectivamente. Años más tarde, en 1893, un grupo de notables, también bajo la tutela de B. Mitre, comenzó a reunirse en forma periódica en el domicilio de Alejandro Rosa con el propósito de debatir aspectos relativos al pasado argentino e intercambiar objetos, medallas y documentos. De esas reuniones surgiría la Junta de Historia y Numismática Americana que, a fines de los años treinta, daría origen a la Academia Nacional de la Historia.

Ante la ausencia de instituciones orgánicas que, en el espacio público, se dedicaran de modo sistemático a la práctica de la Historia, la sociabilidad de sus cultores, hasta la primera década del siglo XX, se limitó a ámbitos particulares. El acceso a documentos, libros y el intercambio de ideas tuvo lugar en las tertulias o reuniones que se desenvolvían en domicilios particulares o incluso en librerías, sobre todo desde mediados de siglo, que constituyeron también espacios para el encuentro de interesados en diversas actividades tanto literarias o artísticas como históricas. En alguna medida, y durante un período extenso de tiempo, la misma Junta de Historia y Numismática participó de esta condición de lugar privado que congregaba a un número limitado de notables.

La creación de la Sección primero, y del Instituto de Investigaciones Históricas más tarde, conllevaba la construcción de un nuevo escenario para la práctica, formación y socialización de los historiadores. En primer término, la Historia consolidaba su perfil como disciplina científica siguiendo así las líneas directrices de un proceso que, en el caso europeo, ya tenía más de un siglo y que había contado a las universidades como ámbito privilegiado. En la década de 1880 había culminado el proceso de conformación del sistema universitario moderno en la Argentina. Las dos casas de altos estudios nacionales existentes por entonces, centraban sus actividades en la formación de profesionales liberales: médicos, abogados y, secundariamente, ingenieros. En ese marco, el espacio para las actividades propiamente 
científicas y humanísticas era considerablemente limitado. Como señalara Juan Carlos Tedesco (1983: 121-129), esta circunstancia obligó a quienes se dedicaban a la práctica de estas últimas a adoptar "una actitud fuertemente vocacional y ascética". Muy tempranamente, esta impronta profesionalista fue fuertemente cuestionada por diversos actores del mundo de la prensa, cultural, y también académico. La necesidad de generar prácticas, instituciones o mecanismos para contrarrestar esta orientación de las universidades, impulsó iniciativas de distinto carácter. Una de ellas culminó con la creación de la Facultad de Filosofía y Letras en el año 1896. Ésta constituiría el lugar para el desarrollo de los "estudios desinteresados" en la UBA y el espacio para la práctica de la investigación científica.

La Facultad estableció tempranamente una estructura curricular que incluía un conglomerado de asignaturas correspondientes a distintas disciplinas: Etnología, Geografía, Historia, Literatura y Filosofía. Posteriormente, serían tres las que predominarían en la organización de los estudios: Filosofía, Historia y Letras. Otorgaba la Institución originalmente un título de Doctor en Filosofía y Letras, pero posteriormente se organizarían tres profesorados en las disciplinas mencionadas. También, algunos años después de la creación de la Facultad, se resolvió asentar formalmente la actividad científica. En 1904 fue creado el Museo Etnográfico. En junio de 1905, el Consejo Directivo aprobó una ordenanza sobre estructuración de trabajos de investigación. El Decano fue autorizado entonces a organizar tareas en este propósito en Geografía, Historia, Lingüística y Etnografía. Se disponía así que por cada una de estas materias se constituyese una Sección de Investigación que integraría a los profesores de la materia y a los adscriptos.

\section{La práctica de la Historia}

La necesidad de avanzar en el proceso de institucionalización de los estudios históricos debe analizarse también en relación con un conjunto complejo de variables, más allá de las determinadas por el contexto y la problemática específicamente universitaria. Por entonces, el mundo cultural porteño era testigo de intensos debates en torno a las condiciones, las técnicas y los procedimientos que debían orientar la práctica de la Historia. En 1896, el mismo año de creación de la Facultad, Paul Groussac, director de la Biblioteca Nacional, publicó un artículo en la Revista de la Institución cuestionando la edición por parte de Norberto Piñero de un volumen que contenía un conjunto de escritos de Mariano Moreno. Groussac criticaba con dureza la publicación de una obra que incorporaba documentos seleccionados y transcriptos sin seguir las reglas del método que regían las prácticas de la profesión histórica. Además y, en forma severa, cuestionaba el dominio, en los espacios consagradas a las actividades humanísticas, de los profesionales liberales, en particular médicos y abogados, subrayando que no era lícito ingresar "por sus dominios como en campo sin dueño o predio de comùn". ${ }^{1}$ Finalmente, objetaba los procedimientos que hacían consistir el mérito de una obra en la posesión "fortuita y clandestina de un testimonio individual".

1 Groussac, P. (1896). “Escritos de Mariano Moreno”. La Biblioteca, Núm. 1, Buenos Aires. Texto extraído de Groussac (1985: 228). 
En este sentido, la creación de la Facultad en primer término, y de la Sección de Investigaciones Históricas después, constituía un primer paso en el intento de desplazar la práctica y la investigación histórica de los circuitos particulares y privados hacia el espacio de los organismos estatales y públicos. Esto permitía, a la vez, independizar -aunque obviamente con límites- la práctica de la disciplina de aquellos núcleos que se anudaban en torno a particulares que eran propietarios de vastas bibliotecas e incluso de fondos documentales que, sólo lentamente, pasaban al patrimonio público. Muchos de estos personajes, además, conservaban lazos directos y estrechos, por origen familiar, con los protagonistas de la historia que estudiaban. La Facultad, la Sección y el Instituto luego permitirían también consolidar un espacio para la formación profesional de los historiadores en gran medida ajena a aquellos ámbitos. De este modo era posible separar la práctica de la investigación histórica de los aficionados, los diletantes, los coleccionistas, los anticuarios o incluso de los descendientes directos de los protagonistas de las luchas políticas de las primeras décadas del siglo XIX.

Pero tampoco puede analizarse el surgimiento de la Sección y del Instituto sin tener presente el papel que la Historia desempeñó en la vida pública. La Historia, desde fines del siglo XIX, se convirtió en una disciplina esencial en el proceso de construcción de una identidad y conciencia nacional. Esto la convertía en un objeto de atención prioritaria por parte de los gobiernos. La Argentina no fue ajena a este proceso, que se vivió en la mayor parte de Occidente. Este papel público y profundamente político fue concebido por entonces como perfectamente compatible con el estatus científico de la disciplina. En 1909, Ricardo Rojas publicó La Restauración Nacionalista. La obra era resultado de un encargo de las autoridades del Ministerio de Justicia e Instrucción Pública, que tenía como objetivo el análisis en Europa de la enseñanza de la Historia, con el propósito de llevar a cabo una reforma de los planes de estudio en el país. Se trataba de fomentar el patriotismo y consolidar el carácter nacional mediante una transformación del sistema educativo. La escuela pública tenía, en este contexto, un papel central en la tarea de contrarrestar los efectos del cosmopolitismo y contribuir a la creación de una comunidad nacional. Pero el interés por la función de la Historia en la transformación del sistema educativo en el nivel primario conllevaba también la inquietud por el modelo de enseñanza de la disciplina en el ámbito universitario. La Facultad debía convertirse así en un baluarte de la educación "nacionalista". Cultivar la ciencia histórica y contribuir mediante esta operación a la creación de un espíritu nacional aparecían entonces conjugados en la nueva etapa que se abría con la creación de la Sección. La Facultad misma había sido creada por el propósito de construir un corpus de conocimientos en el ámbito de las disciplinas humanísticas sobre los problemas nacionales. Rojas señalaría en la obra antes mencionada que la Facultad adoptaba la "orientación nacionalista", compatible con los altos estudios universitarios y que la Escuela de Historia, que proponía crear allí en su "faz política”, constituiría el "órgano de la restauración nacional” (Rojas, 1909: 442). 


\section{Proyectos institucionales: investigación en archivos, difusión y edición de documentos}

Tempranamente, desde la Sección se diseñó un ambicioso plan de investigación en bibliotecas y fondos documentales, que debería cristalizar en una serie de publicaciones. Durante sus primeros años de existencia, la indagación en archivos, la selección de documentos -siguiendo las pautas de la crítica de fuentes desarrolladas a lo largo del siglo XIX- y su publicación en series organizadas temáticamente, constituyó el eje fundamental de las tareas de los miembros de la Sección y luego del Instituto. Esa era también la función que asumieron las primeras instituciones consagradas a la investigación histórica en Europa que llevaron a cabo grandes proyectos de selección, compilación y publicación de documentos originales. En el caso de la Sección se manifestó explícitamente el propósito de realizar estos trabajos siguiendo los métodos de crítica que se difundieron en la Argentina a través de manuales franceses y españoles. En marzo de $1906 \mathrm{el}$ Consejo Directivo de la Facultad resolvió impulsar el inicio de las actividades de la Sección proyectando la edición de tres volúmenes de documentos provenientes del Archivo de la Provincia de Catamarca. Nora Pagano y Miguel Galante (1993) han llamado la atención sobre el hecho de que el Consejo Directivo de la Facultad desestimó, en esa oportunidad, la idea de redactar una Historia de la República Argentina, ya que predominó entonces el criterio del profesor Clemente Fregeiro, quien insistió en que para llevar a cabo una obra de esa naturaleza era preciso agotar antes las consultas en fuentes inéditas.

Los documentos del archivo de Catamarca fueron finalmente entregados, pero la obra no se llevó a cabo. Unos meses más tarde, el entonces Decano, José Nicolás Matienzo, elevó una circular a los profesores de Historia de la Facultad, invitándolos a iniciar la búsqueda y selección de documentos relativos a la época de la Organización Nacional. Sostenía el Decano, que además era un reconocido especialista en Derecho e Historia Constitucional, que habiendo transcurrido más de un cuarto de siglo del fin de esa etapa, había llegado el momento de reunir los materiales que los futuros historiadores requerirían para la narración y crítica imparcial de aquellos acontecimientos. La postergación de esa búsqueda, sostenía, podía acarrear la pérdida de importantes fuentes de información. Las investigaciones se iniciaron a fines de 1906, siguiendo sus indicaciones. Desde la Facultad se llevaron a cabo además gestiones ante distintos gobiernos provinciales para poder obtener documentación original. Finalmente, la Sección logró designar al sacerdote Antonio Larrouy para que llevara a cabo indagaciones en los Archivos de Paraná y Santa Fe. Larrouy elaboró un informe que se publicó en la Revista de la Universidad de Buenos Aires (RUBA). Allí reconoció que había sido comisionado para copiar sobre todo en los archivos de Paraná documentos relativos a la caída de Rosas y al establecimiento de la capital de la República y subrayó que se le había exigido llevar a cabo su investigación sin condicionamientos partidarios. ${ }^{2}$

2 "Investigaciones Históricas de la Facultad de Filosofía y Letras. Informe del Comisionado P. Antonio Larrouy sobre los Archivos de Paraná y Santa Fe", en Revista de la Universidad de Buenos Aires, Tomo IX, Buenos Aires, 1908, pp. 98-118. 
Las investigaciones se trasladaron luego a los archivos de Córdoba y de Tucumán. Un año después, en 1909, fue Emilio Ravignani, incorporado como adscripto a la Sección, quien continuó con las tareas de búsqueda de documentación correspondiente al período comprendido entre los años 1851 y 1853 en el archivo de Paraná. Ravignani se había dedicado fundamentalmente a copiar las comunicaciones realizadas por los gobiernos provinciales que habían integrado la Confederación Argentina y sus búsquedas, sostenía, le habían permitido constatar el deseo ferviente de los pueblos del interior por organizarse institucionalmente. En la carta elevada al Decano, sostenía Ravignani que la Historia Argentina, impregnada en gran medida por la perspectiva de un partido político, requería ser completamente rehecha. En este sentido, destacaba que, merced a la orientación que predominaba en las cátedras de Historia de la Facultad, era posible iniciar una serie de trabajos sobre los documentos con un criterio científico y nacional utilizando los métodos que habían sido difundidos en el país por el historiador y académico español Rafael Altamira. De este modo, además, ya uno de los principales colaboradores de la Sección volvía a subrayar la necesidad de construir una nueva aproximación a la historia nacional al margen de las controversias políticas y partidarias que habían, desde su perspectiva, afectado negativamente los relatos predominantes hasta entonces. ${ }^{3}$

En octubre de 1912, la Sección fue reestructurada. Luis M. Torres fue designado director y Emilio Ravignani encargado de Investigaciones. En 1914 se incorporarían como adscriptos honorarios Rómulo Carbia y Diego L. Molinari, y en 1915, Carlos Correa Luna. Durante estos años, la Sección dio inicio a su dinámica política de publicaciones que le otorgó un sello distintivo. A los informes de Larrouy, se sumó en 1910 la edición de Gobierno del Perú, obra escrita en el siglo XVI por el licenciado Juan Matienzo, ascendiente del entonces Decano. En 1911 se inició la publicación de los Documentos relativos a la Organización Constitucional de la República Argentina. A partir de 1912 se publicaron los Documentos relativos a los antecedentes de la Independencia de la República Argentina. Ese mismo año vio la luz la serie Documentos para la Historia del Virreinato del Río de la Plata, que incorporaba fuentes sobre su etapa fundacional. En 1913 se inició la publicación de la colección quizás más conocida del Instituto: Documentos para la Historia Argentina. Los primeros tomos incluían sobre todo fuentes relativas al período colonial. En relación a esta última serie, cabe señalar dos cuestiones fundamentales. Por un lado, puede advertirse cómo se fortalecía la tendencia a desplazarse desde el período de la organización nacional hacia la etapa virreinal, expresando los intereses del nuevo director de la Sección Luis M. Torres; y por otro, se nota el intento de ampliar los horizontes de los temas de indagación desde dimensiones políticas e institucionales hacia aspectos más amplios de la experiencia histórica, incluyendo cuestiones relativas a la vida cotidiana o a las prácticas económicas. Juan Agustín García, en la introducción de uno de estos volúmenes, sostendría que las publicaciones de la Sección mostraban el profundo cambio que estaba experimentando la ciencia histórica argentina, que pasaba de una 
historia fundamentalmente política y militar a otra en la que los detalles de la vida cotidiana de los hombres cobraban un interés central (García, 1914: 7).

En el tomo V, publicado en 1915, Luis M. Torres presentó, a través de una advertencia, un plan de publicaciones que abarcaba un núcleo amplio de dimensiones de la historia virreinal. Comenzaba con el estudio del territorio y culminaba con los aspectos culturales, atravesando las cuestiones relativas a la población, a la organización productiva y a la constitución política y administrativa (Torres, 1915: XIII-XV). En 1916, al participar colectivamente los miembros de la Sección en el Congreso Americano de Ciencias Sociales celebrado en Tucumán, tanto Torres como Ravignani expusieron diversos argumentos para justificar la prioridad otorgada a los estudios sobre el período virreinal. El primero sostenía que se trataba de una época "mal documentada" y en la que se encontraban los antecedentes de las principales instituciones argentinas. Ravignani, por su parte, subrayaba, por un lado, que era el período generador de la vida independiente "fin último de todo estudio de historia argentina”, y por otro, que el conjunto más amplio y completo de documentos sobre la época colonial conservados en archivos nacionales se refería al Virreinato (Ravignani y Torres, 1917: 323-328).

Otro aspecto fundamental sobre el que insistirían en sus intervenciones tanto Torres como Ravignani remitía a los procedimientos que estructuraban las tareas de investigación y los desafíos que debían afrontar los especialistas. Ravignani subrayaba la ausencia de catálogos en los archivos, fundamentalmente en los del interior, que imposibilitaba tener una noción del tipo de documentos contenidos en los diferentes legajos. La reorganización de los archivos y la divulgación de los contenidos a partir de la conformación de nuevos registros aparecía como una tarea urgente. Otros de los integrantes de la Sección insistieron en la necesidad de llevar a cabo una rigurosa tarea bibliográfica previa a la recolección de documentación. También afirmaban que los trabajos de indagación eran realizados con "entera prescindencia" de todo lo que no estuviera determinado por una rigurosa disciplina científica. Finalmente, sostenían la necesidad de construir colecciones de fuentes para uso de los alumnos de las escuelas secundarias. Un año después, los integrantes de la Sección publicaron un Manual de Historia de la Civilización Argentina, que elaboraron con materiales propios y presentaron como la "síntesis y cristalización” de las investigaciones de orden bibliográfica y documental llevadas a cabo. Defendieron aquí un concepto particular del sentido de la Historia. Por un lado, la idea de civilización que expresaba la voluntad de contemplar el estudio de amplias dimensiones de la vida del pasado, tanto las militares como las relativas al arte, la literatura, la economía, la organización social, el espíritu religioso, la industria y el comercio. Por otro, situaban al concepto de serie histórica como una dimensión fundamental. Se afirmaba entonces que la Historia era una ciencia que investigaba y establecía la causa y el efecto de los hechos históricos y los ordenaba dentro de series. Éstas, a la vez, conformaban familias de hechos. La investigación de las causas que provocaban los acontecimientos, sus consecuencias y el lugar que ocupaban en la serie debía realizarse, a la vez, con absoluta "prescindencia de fallos favorables o desfavorables a los hombres y las cosas” (Torres, Carbia, Ravignani y Molinari, 1917). 
Como ya señalamos, la creación de la Sección permitió configurar un ámbito en el que los cultores de la Historia como disciplina científica pudiesen separarse de los aficionados, de los anticuarios, de los bibliófilos y coleccionistas. Al mismo tiempo, permitiría escindirlos de las facciones políticas -ligadas a los protagonistas de la historia- que habían construido relatos que consideraban objetables del pasado argentino. Gracias a esta creación, la Historia reafirmaba su nueva jerarquía como disciplina universitaria. Por entonces, ya se había independizado de modo sólido y consistente en la estructura curricular universitaria de la Literatura y la Filosofía. Por otro lado, también estos procesos le permitían consolidarse como una asignatura independiente del estudio del Derecho al que, de todas formas, por los orígenes profesionales de los miembros de la Sección, seguía estrechamente vinculada. La afirmación dentro del contexto universitario posibilitaba además formalizar criterios, pautas y elaborar planes de trabajo de mediano y largo plazo.

\section{De la Sección al Instituto}

En diciembre de 1921, la Sección se convirtió en el Instituto de Investigaciones Históricas. Como ya señalamos, esta transformación tuvo lugar en un contexto más general de institucionalización de la ciencia en el ámbito de la UBA que siguió a la Reforma Universitaria de 1918. El Instituto reunió a un grupo sólido de investigadores que, mayoritariamente, ya colaboraban en la Sección. Varios de ellos provenían de las disciplinas liberales, en particular del Derecho y se habían especializado en cuestiones relacionadas con la Historia Constitucional. Si bien los lazos con las élites gobernantes durante el Antiguo Régimen son menos evidentes que los que se notan entre quienes frecuentaban las reuniones de la Junta de Historia y Numismática Americana, también puede advertirse que varios de ellos ejercerían funciones relevantes en la vida pública. Emilio Ravignani, quien ya había sido designado director de la Sección meses antes de su transformación en Instituto, fue Subsecretario de Hacienda de la ciudad de Buenos Aires durante la presidencia de Marcelo T. De Alvear. Sería éste el primer paso en una larga carrera política dentro de la facción alvearista de la Unión Cívica Radical, que lo llevaría a ocupar la plaza de diputado nacional entre 1936 y 1943. A esto se sumaría una destacada trayectoria en la propia UBA, en la que ocupó los cargos de Decano de la Facultad de Filosofía y Letras entre 1927 y 1930 y entre 1940 y 1943, e incluso de Rector interino durante un muy breve período. Su trayectoria se cruza con la de otro de los reconocidos colaboradores del Instituto, Diego Luis Molinari, quien ejerció el puesto de Subsecretario de Relaciones Exteriores durante la Presidencia de Hipólito Yrigoyen y que también ocuparía más tarde los de diputado y senador nacional. Quizás una excepción en términos formativos y de trayectoria fuese la de Rómulo Carbia. Autor, probablemente, de la primera historia de la historiografía argentina, Carbia había cursado estudios de Historia en la Universidad de Sevilla donde, además, había obtenido un Doctorado. De todos modos, sería también una figura destacada entre los círculos relacionados con el catolicismo local. 
La nueva condición institucional no modificó de modo sustantivo ni el ritmo ni las actividades que venían desarrollándose desde la década anterior. Las publicaciones de la Sección ya habían alcanzado, a fines de la década de 1910, un impacto significativo, no sólo dentro de la Argentina sino también en ámbitos académicos externos. En febrero de 1921, la historiadora norteamericana Irene A. Wright publicó en The Hispanic American Historical Review una breve nota en la que destacó la importancia de las colecciones documentales. Señaló en este contexto, por un lado, que lo que las caracterizaba era sobre todo el hecho de que se hubiesen originado en un cuidadoso plan y, por otro, que pretendiesen abarcar todos los factores históricos presentes desde la colonización de América. Las publicaciones permitían, además, advertir el grado de perfección que las tareas de investigación histórica habían adquirido en la Argentina. ${ }^{4}$

Durante los años '20, el Instituto se convirtió en centro de colaboración, recepción y distribución de información para instituciones e individuos dedicados o interesados por la investigación histórica tanto del interior como del exterior. Su nueva condición y su reconocimiento público se consolidaron al aparecer, en 1922, el Boletín del Instituto de Investigaciones Históricas, que se sumaba así a las series de publicaciones. El propósito de la nueva revista consistía en dar a conocer relaciones documentales, noticias bibliográficas y proporcionar información relativa a las actividades del Instituto. Se trataba, probablemente, del primer intento en la Argentina de mantener una publicación periódica especializada en el saber histórico y seguramente fue la primera revista académica dedicada integralmente a la disciplina en el país.

Como ya señalamos, el modelo de trabajo y los programas de investigación del Instituto siguieron conservando la impronta definida en los orígenes de la Sección y consolidada con el plan de publicaciones de 1915. La búsqueda, selección, compilación y edición documental continuó conformando, durante un largo período, un elemento central en la constitución del perfil profesional de los historiadores argentinos, como lo había sido en Europa desde mediados del siglo XIX. De todos modos, la antigua orientación hacia los estudios coloniales y el período virreinal fue sustituida por otra más afín a las preocupaciones temáticas del nuevo director. Ya al hacerse cargo de la dirección, las principales inquietudes historiográficas de Ravignani se relacionaban con el estudio del período abierto en 1820 y que culminaba, desde su perspectiva, con la caída del gobierno de Juan Manuel de Rosas en 1852. En este contexto, las cuestiones relacionadas con el papel jugado por los caudillos provinciales se convertirían en el centro de los trabajos del Instituto.

La búsqueda y recopilación de documentación relativa a estos problemas conformaron ejes del trabajo del Instituto en los años '20. La correspondencia de Emilio Ravignani con los copistas de documentos en archivos del Interior y el Litoral, que puede consultarse tanto en los libros copiadores como en el mismo archivo del Instituto, permite obtener una primera aproximación a la nueva orientación que 
primó en estas actividades. En este contexto, es particularmente útil seguir las instrucciones enviadas a Andrés Figueroa y, sobre todo, a Eduardo Fernández Olguín. A principios de los '20, se le indicó a este último que debía buscar documentación correspondiente a José Artigas en los archivos de las provincias de Córdoba y en las del Litoral, particularmente en Corrientes. Luego se le pidió que indagara en aquellas fuentes vinculadas con la llamada Liga Litoral y el Pacto Federal de 1831. ${ }^{5}$ A mediados de los años '20, Fernández Olguín se trasladó sucesivamente a Mendoza, Salta y Jujuy para obtener testimonios relativos a las constituciones provinciales sancionadas a partir de 1820. Ravignani le manifestó entonces su interés por el estudio del origen de las autonomías provinciales. De esta manera, el director imprimió a las actividades del Instituto un sello particular, asociado en forma directa a sus preocupaciones que, a su vez, estaban estrechamente relacionadas con sus intereses como historiador del Orden Constitucional Argentino y como profesor de Historia Constitucional de la Facultad de Ciencias Jurídicas y Sociales de la Universidad Nacional de La Plata. Los problemas relativos a los orígenes de las autonomías provinciales, a la conformación y construcción del orden federal y a la acción de Artigas y los caudillos, constituían por entonces los ejes centrales de sus investigaciones. En este marco, Ravignani se esforzó por diseñar una interpretación del pasado argentino que subrayó el aporte de las provincias y los caudillos, en particular de Artigas a la construcción del orden consagrado en la Carta de 1853 y sus sucesivas reformas. La crítica a una historiografía de partido que refiere probablemente a la obra de Vicente Fidel López y, sobre todo, a cierta tradición manualística de la Historia Constitucional cristalizada en el texto de Aristóbulo del Valle, aparecen como aspectos característicos de su obra. Una nueva lectura del período y de la figura de Juan Manuel de Rosas se articula también en este marco. La reedición, por parte del Instituto en 1923 de La época de Rosas, de Ernesto Quesada, al cumplirse 25 años de su primera edición, y que sería considerada tiempo más tarde como una de las primeras reivindicaciones del personaje, es particularmente significativa en este contexto.

\section{En una coyuntura crítica: el Instituto en los años treinta}

Los acontecimientos del año 1930 impactaron de modo sustantivo en las actividades del Instituto. El problema central no radicó tanto en el efecto de los cambios políticos provocados por el golpe de Estado del 6 de septiembre de ese año, ya que Ravignani, reconocido dirigente de la Unión Cívica Radical, conservó su lugar como director, sino fundamentalmente en los condicionamientos que impuso la crisis económica. En su correspondencia resaltaría, de modo permanente, las dificultades financieras que afrontaba y cómo éstas impedían la publicación de volúmenes listos para ser editados y distribuidos. La escasez de recursos llegó a un punto particularmente grave en 1933. Entonces, reconoció Ravignani que aquellos habían disminuido en un 30\% y que estas restricciones habían impedido incorporar nuevos investigadores. A principios de 1935, se vería obligado a 
rechazar la solicitud de Enrique Barba -quien sería tiempo más tarde una figura central en el proceso de institucionalización de los estudios históricos a partir de su actividad en la Academia Nacional de la Historia y en la Universidad Nacional de la Plata- de incorporarse al Instituto, por razones justamente presupuestarias. En este sentido, es preciso destacar que las ambiciosas empresas editoriales del Instituto, que impulsó durante el cuarto de siglo que ejerció la dirección, sólo fueron posibles gracias a la asignación de cuantiosos fondos. A la vez, sólo es posible pensar en esa capacidad de obtención de recursos vinculándola con su actividad pública en el ejercicio de cargos partidarios, legislativos, universitarios y también a partir de su intervención activa en los principales diarios de circulación nacional, en particular en La Nación.

Fue justamente, a mediados de esa década, cuando los problemas comenzarían a solucionarse. En este sentido, es importante tener presente la intervención personal del entonces Presidente de la Nación, Agustín P. Justo, quien se ocupó de asegurar fondos para que el Instituto pudiese dar un nuevo impulso a sus actividades. El interés de Justo se explica en cierta medida por su propia afición a la Historia, pero también por el vínculo personal con Ravignani, anudado probablemente en los tiempos en que ambos habían sido funcionarios del gobierno de Marcelo T. De Alvear. Por supuesto, seguramente incidía también de modo decisivo el papel que la Historia seguía ejerciendo en la esfera pública y en la que, en el favor del Estado, el Instituto competía, con desventaja, probablemente, con la Junta de Historia y Numismática Americana. En abril de 1934, por iniciativa de Justo y a través de un acuerdo de Ministros, se le asignó al Instituto una suma especial de treinta mil pesos para continuar con las tareas de publicaciones. La posibilidad de influir sobre distintos actores con peso e influencia en los organismos del gobierno y del Estado cobró seguramente un nuevo impulso cuando Ravignani mismo fue electo diputado nacional en 1936.

Estos fondos le permitieron al Instituto no sólo continuar con su serie de publicaciones sino también mantener las actividades de copia de documentos en archivos tanto provinciales como del exterior. Desde 1918 el Instituto solventaba las actividades de José Torre Revello, quien copiaba documentación en el Archivo de Indias de Sevilla. Además, recibía copias de archivos franceses y alemanes. En 1932 se había incorporado un investigador para trabajar en repositorios documentales ingleses, y en 1935 otro para recopilar fuentes en el archivo de la ciudad de Río de Janeiro.

Pero, sin duda, el acontecimiento que, en términos editoriales, ocupó el centro de la vida del Instituto durante aquellos años fue la edición de los tomos de Asambleas Constituyentes Argentinas. La obra se preparó a partir de 1935 y los primeros tomos comenzaron a distribuirse dos años más tarde. Allí se dieron a conocer también gran parte de los documentos recuperados en archivos provinciales. La iniciativa partió de un diputado nacional por el Partido Socialista, Juan A. Solari quien, en 1933 propuso, como manera de conmemorar los ochenta años de la promulgación de la Constitución Nacional, la publicación de una obra que reuniese en un solo cuerpo los debates de las Asambleas Constituyentes y los textos 
legales, "ilustrativos y básicos", que diesen cuenta de la formación de la unidad y estructura política argentina. Solari consultó a Ravignani sobre la posibilidad de que el Instituto asumiese el proyecto y, aparentemente, éste aceptó el convite sin reservas. La propuesta se presentó en la Cámara de Diputados y luego pasó a la de Senadores. Finalmente, una ley del Congreso Nacional de julio de 1934 hizo posible avanzar con la edición. Se estableció que la compilación y edición de documentos y textos de debates sería efectuada por el Instituto, mientras que los gastos que demandase provendrían de rentas generales. La obra contó con un apoyo sostenido por parte de las autoridades nacionales y los recursos invertidos fueron cuantiosos, sobre todo si se tiene presente su magnitud, el número de ejemplares y el hecho de que gran parte de lo editado se distribuyó de modo totalmente gratuito. Ravignani prologó varios de los volúmenes y allí editó gran parte de la documentación recopilada desde los años veinte y que, en gran medida, aún permanecía inédita. A través de estos prólogos expuso, además, sus ideas principales sobre la organización constitucional argentina. Asambleas Constituyentes fue, sin duda, la principal de las numerosas iniciativas editoriales que el Instituto llevó a cabo durante la primera etapa de su constitución. Aún hoy constituye una fuente de referencia ineludible para todos aquellos interesados en la historia política rioplatense de la primera mitad del siglo XX.

El Instituto logró desarrollar también sus tareas gracias a las sólidas redes nacionales fundamentalmente, pero también internacionales en las que estaba inserto. En alguna medida estas mismas redes se confundían con las que su propio director construía gracias a sus fluidos contactos en el gobierno, en la administración pública y en la misma UBA. Como ya señalamos, consideramos que cualquier estudio de los desafíos y obras desarrolladas en la etapa fundacional del Instituto debiera situar, en un primer plano, la condición de dirigente político y universitario de su director. Esto permitió, entre otros aspectos, allanar al Instituto el acceso a los archivos, pero si duda también obtener los recursos que permitieron que se transformarse en un organismo de referencia, seguramente el más importante del país en el ámbito universitario, en lo que respecta a los estudios históricos.

\section{Consideraciones finales}

Hacia finales de la década de 1930, el Instituto contaba ya con medios relevantes, con una larga serie de publicaciones y con un núcleo de reconocidos investigadores asociados. En particular su director, E. Ravignani, intervenía con frecuencia en las polémicas sobre el pasado, conservando una notable presencia en los principales periódicos como La Nación y la Prensa. El Instituto había logrado alcanzar un lugar preeminente en la esfera pública debido seguramente también al papel que la Historia desempeñaba en la construcción de la identidad y la conciencia nacional. Esta última circunstancia es fundamental para comprender el impacto público de las actividades desarrolladas y expresadas sobre todo a partir de su intervención como asesor de organismos públicos, que debían cristalizar una 
lectura del pasado en medidas institucionales como los nombres de calles, la construcción de monumentos o la determinación de efemérides.

Como ha destacado Alejandro Cattaruzza (2001: 429-476), en aquellos años el escenario relacionado con la práctica de la Historia se pobló de nuevos actores e instituciones que competían por el favor del Estado y por sus recursos. De todas formas, en su función como Institución de referencia en lo que respecta a la disciplina histórica, el Instituto se encontró sobre todo con un contendiente de peso: la Junta de Historia y Numismática Americana, que consolidó su condición de organismo público al transformarse oficialmente en la Academia Nacional de la Historia en enero de 1938. Fue esta última, en realidad, la encargada de elaborar y publicar la Historia de la Nación Argentina, obra monumental y en varios volúmenes, cuya edición insumió varios años, mostrando, posiblemente, su mayor cercanía y sensibilidad a las demandas provenientes del Estado. En este sentido, la trayectoria del Instituto durante esos años muestra el esfuerzo por convertirse en un organismo de referencia en la producción histórica en un marco de una fuerte competencia institucional que, en alguna medida, puede confundirse con la disputa entre sus principales figuras: Emilio Ravignani, por un lado, y Ricardo Levene, Presidente de la Academia Nacional de la Historia, por otro. En este sentido, Ravignani mostró posiblemente un mayor grado de autonomía y diferenciación con respecto a los gobiernos y al Estado durante los años treinta. Seguramente también incidía en este caso, de modo desventajoso, su condición de dirigente político opositor y la mayor autonomía que la dependencia universitaria le otorgaba al Instituto.

El Instituto contribuyó de manera decisiva a la construcción de la profesión de historiador en la Argentina de la primera mitad del siglo XX. Procuró afirmarla, como había acontecido en Europa desde principios del siglo anterior, en base a los métodos de crítica documental. Sus integrantes y, en particular su primer director, aspiraron a construir un ámbito para la práctica de la Historia desvinculado de las redes construidas por los descendientes de quienes habían protagonizado las luchas políticas de la primera mitad del siglo XIX. Además aspiraron a contribuir a la construcción de una conciencia nacional a través de la disciplina. Se los cuestionó retrospectivamente, en más de una oportunidad, por haber privilegiado estos aspectos metodológicos y no haber renovado ni los temas ni las preguntas con las que se dirigieron hacia el pasado. Los primeros y tímidos intentos por avanzar en una historia de la población, de los circuitos productivos, de los aspectos culturales y las ideas, quedaron desplazados a un segundo término. La historia económica, que afirmaron practicar, quedó presa en más de una oportunidad de los estudios institucionales a través del análisis de la evolución de las leyes o normativas relacionadas, entre aspectos, con el comercio o las actividades económicas en general. Pero tal vez se trate también de un cuestionamiento injusto. Construir una profesión de historiador en la Argentina de aquellos tiempos era una empresa compleja que se afirmaba entre agudas tensiones. Diferenciar a la Historia del ejercicio de la Literatura, de la especulación política o filosófica más pura, del ensayismo, pero también de los anticuarios o los bibliófilos, constituyó sin duda una tarea y un desafío extremadamente difícil y complejo en la Argentina de principios del siglo XX. 


\section{Q Bibliografía}

" Buchbinder, P. (1996). Vínculos privados, instituciones públicas y reglas profesionales en los orígenes de la historiografía argentina. En Boletín del Instituto de Historia Argentina y Americana E. Ravignani. N 13, 3. Serie. pp. 59-82.

" Buchbinder, P. (1997). Historia de la Facultad de Filosofía y Letras. Buenos Aires: Eudeba.

"Cattaruzza, A. (2001). Descifrando pasados: Debates y representaciones de la Historia Nacional. En Cattaruzza, A. Crisis Económica, avance del Estado e incertidumbre política. Buenos Aires: Editorial Sudamericana, pp. 429-476.

"Fernández Olguín, E. (1921). Los archivos de la ciudad de Corrientes. Buenos Aires: Coni

" García, J. A. (1914). Introducción. En Facultad de Filosofía y Letras. Documentos para la Historia Argentina, T. IV, Buenos Aires, Compañía Sud-Americana de Billetes de Banco, p. IX-XV.

" Groussac, P. (1985). Crítica Literaria. Buenos Aires: Hyspamérica.

" Pagano, N. y Galante, M. (1993). La Nueva Escuela Histórica: una aproximación institucional del Centenario a la década del '40. En Devoto, F. (comp.). La Historiografía Argentina en el siglo XX. T. I, Buenos Aires: Centro Editor de América Latina, pp. 45-77.

"Pompert de Valenzuela, M.C (1995). El Instituto de Investigaciones Históricas de la Facultad de Filosofía y Letras de la Universidad de Buenos Aires. En AAVV (1995). La Junta de Historia y Numismática Americana y el movimiento historiográfico en la Argentina (1893-1938). Buenos Aires: Academia Nacional de la Historia, pp. 251-270.

" Ravignani. E. y Torres, L. M. (1917). El material histórico, la investigación correlacionada con los factores y los elementos bibliográficos. En Memoria del Congreso Americano de Ciencias Sociales. Buenos Aires: Impr. J. Tragant, pp. 323-328.

" Rojas, R. (1909). La Restauración Nacionalista. Buenos Aires: Ministerio de Justicia e Instrucción Pública.

" Tedesco, J. C. (1983). La Universidad y su Reforma. En Romero, J. L y Romero, L.A. Buenos Aires: Historia de 4 siglos, Tomo II. Buenos Aires: Editorial Abril, pp. 121-129.

" Torres, L. M. (1915). Advertencia. En Facultad de Filosofía y Letras. Documentos para la Historia Argentina, T. IV, Buenos Aires, Compañía Sud-Americana de Billetes de Banco, pp. XIII-XIV.

" Torres, L. M., Carbia, R., Ravignani, E. y Molinari, D. L. (1917). Manual de Historia de la Civilización Argentina. Buenos Aires: Franzetti y Cia. 